\title{
A Sustainability Total Management Model Applied to the Product Life Cycle
}

\author{
Anthony David Johnson \\ Seoul National University of Science and Technology, Seoul, S.Korea
}

\begin{abstract}
In this worldwide consumer society the quest for new and more sophisticated products is ever present often leaving an unsustainable toll on the Earth's resources to the point where some commodities are reduced to levels of scarcity. The growing challenge for product creators is to provide new products that have the least impact on the environment. The need for sustainable products is growing annually but often product creators are either unwilling to engage or are uninformed as to how to engage with the sustainable creation processes. There is a requirement for a cohesive management strategy that can both inform industrialists and provide the tools for the implementation of a sustainable approach to product design and the product life cycle. This paper reviews several publications and builds on previous work (Johnson, Gibson, \& Barrans, 2011), enhancing the commonly used Life Cycle Analysis (LCA) and creating a complete management strategy, which is the Sustainability Enhancement Program (SEP). This incorporates ISO Standards as an operating platform. Embodied Energy (Ashby, 2012) is used as a metric by SEP so that the value of energy input within any product can be measured and reduced in the future product iterations.
\end{abstract}

Keywords: sustainability, Embodied Energy, ISO 14001, ISO 14040 Environmental Management

\section{Introduction}

Life Cycle Analysis is generally used to describe the cycle from material sourcing through to end-of-life disposal for a product. The current proposal is to improve the life cycle analysis structure by adding three more elements: Sustainable Design, Sustainable Maintenance, and Sustainable Giveback. The whole of the product life cycle now comprises seven elements, listed below:

- sustainable sourcing

- sustainable design

- sustainable manufacture

- sustainable usage

- sustainable maintenance

- sustainable disposal

- sustainable giveback

Maintenance has been applied since machinery was first used and is a standard method of improving the longevity of a product, and it has rarely been used as an implement to improve sustainability. Maintenance

Anthony David Johnson, Ph.D., M.I.Mech.E, C.Eng. FHEA, Seoul National University of Science and Technology, Seoul, S.Korea.

Correspondence concerning this article should be addressed to Anthony David Johnson, Ph.D., C.Eng. M.I.Mech.E, 232 Gongneung-ro, Nowon-gu, Seoul, 139-743, S.Korea. 
extends the life of a product, thereby avoiding the procurement of new products and resources. The sourcing energy saved in prolonging the life of a product can be used to offset the energy used in creating the original product. This constitutes "Giveback" which can also include energy saved in recycling materials and reusing components. Giveback and maintenance have been the subject of previous work (Johnson et al., 2011). It has also been previously proposed that a metric of Embodied Energy should be used in order to quantify the value of sustainability in each phase of the life cycle.

The design function is in a position to overview all seven life cycle elements of the product creation process and design-in features that will reduce Embodied Energy input. The design function is the only element in the entire life cycle that can manage and perform this task. Previous work (Johnson \& Mishra, 2013) reported on a Total Design Control Management Strategy (TDCMS) was guided by the design process.

It is convenient to break down a product life-cycle into two phases. Phase 1 Life Cycle covers the Embodied Energy input from sourcing material when the product leaves the factory. This distinction has been made because energy input up to this point can be measured reasonably accurately. Phase 2 Life Cycle is difficult to measure and becomes more of a predictive exercise, as explained below.

\section{Introduction of Total Design Control Management Strategy (TDCMS)}

The Total Design Control Management Strategy (TDCMS) influences the entire life cycle of a product but has most impact on Phase 1 Life Cycle where measurement and direct management of Embodied Energy is more defined.

Phase 2 Life Cycle is harder to measure than Phase 1 Life Cycle since the product is in the hands of the consumer who may or may not use the product as the designers' original intention. Nevertheless systems need to be in place so that there is data feedback from Phase 2 Elements to the TDCMS enabling product iteration and improvement during future Phase 1 Life Cycle creation.

As each stage of the Phase 2 Life Cycle is experienced by the product, the system should allow information to flow back into the TDCMS. This usually happens when the product is maintained. Maintenance procedures collect information which can be fed back to the TDCMS and furthermore allows the replacement of elements such as sacrificial components so that there is not only information flow but mass/component flow into and out of the maintenance process. Figure 1 shows a diagram defining maintenance as a primary hub feature of the Phase 2 Life Cycle.

After several maintenance procedures the product may be refurbished which is effective maintenance at a much deeper level. Refurbishment requires that major parts are completely renewed/repaired and the product is returned to service in an "as-new" condition. Refurbishment can also create data to feed-back information for the TDCMS and the design function, but there is also a major flow of parts and materials into, as well as, out of the process. Parts used components and assemblies may also be collected and passed back to the maintenance procedure so that they can be reused. Also at the refurbishment stage parts which are no longer useful can be collected and recycled. Refurbishment processes have therefore been incorporated as part of the hub element also shown in Figure 1.

Takata (2013) suggested planning of the product life cycle using "Circular Manufacturing”. This integrates maintenance strategies with reuse of components that still possess "residual life". The goal of Circular Manufacturing is as the feedback to reuse all those components and materials which possess "residual life" and feed forward end-of-life components for recycling. These notions have been integrated into the TDCMS. 
In consideration of the need for the TDCMS to record and assimilate information to engage new design strategies, the processes from sourcing to manufacture (Phase 1 Life Cycle) and from usage to disposal (Phase 2 Life Cycle) have been compiled into the TDCMS flow control process set out in Figure 2.

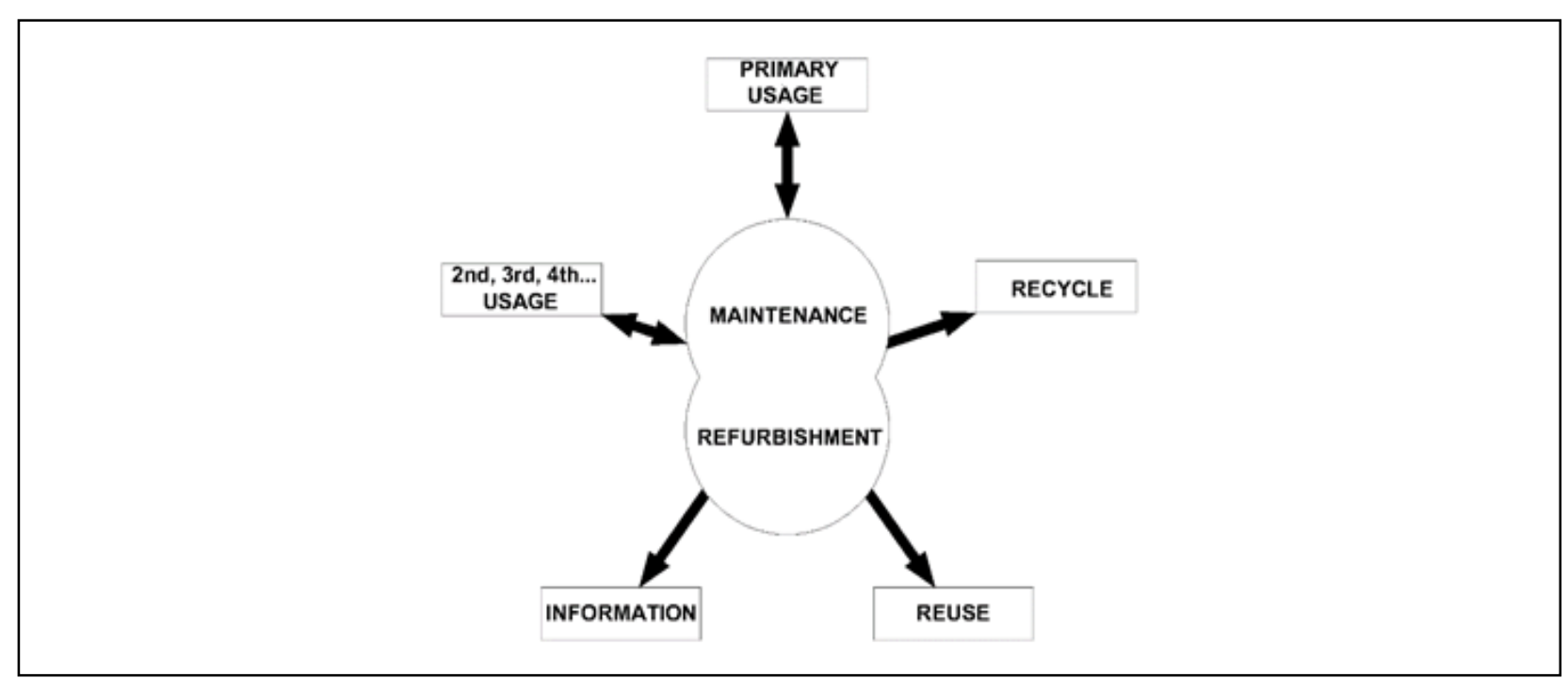

Figure 1. Maintenance and refurbishment as a hub element of phase 2 Life Cycle.

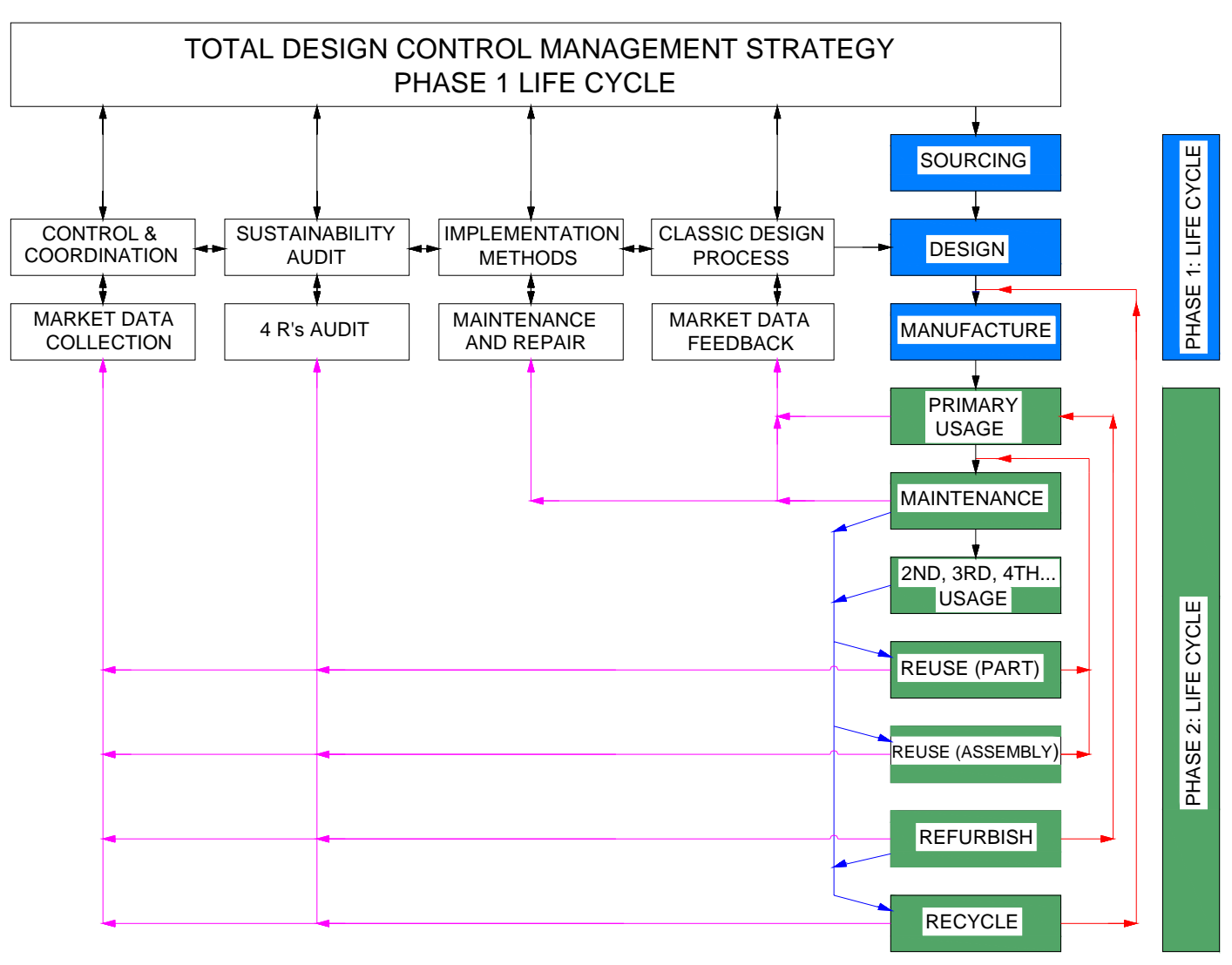

Figure 2. TDCMS flow control process.

Note. Blue arrows: recyclable materials feed forwards; red arrows: reusable components and materials feed backwards; magenta arrows: information feedback. 
The Phase 2 Life Cycle is shown so that the usage, maintenance, and refurbish processes are set out in a systematic order. These are then linked to the Phase 1 Life Cycle elements that define their position within the TDCMS as a whole system.

The diagram in Figure 2 shows that there are essentially three evidential elements emanating from the Phase 2 Life Cycle process. These are itemised below:

- Materials Feed Forward

- Materials Feed Backward

- Data Feedback

Processes such as maintenance and refurbishment will remove worn and part-worn components and feed them forward to be reused or recycled. Though this is the materials feed forward element from each process there may also be a feed-backward element where part-worn components and newly refurbished products are reintroduced to the "Usage Chain". Data feedback is a necessary requirement since there is no design of new components, no input and no basis for improvement.

\section{Recyclable Materials Feed Forwards}

When maintenance is actioned on a product, sacrificial components such as bearings and seals are removed and replaced. Depending on their condition the removed sacrificial elements may be reused or recycled. In the latter case material from maintenance is fed forward towards the end of the life cycle. Maintenance may be performed several times during the usage stage each time extending the life of the product.

At some point the product will require a major overhaul. This refurbishment is a much deeper process than maintenance and replaces components that normally are not replaced during maintenance. The process may involve dismantling the whole product and perhaps re-machining components or welding elements which are signs of fatigue cracking. The outcome is that the product is returned to use as-new. The process generates many part worn components which may be reused and fed forwards for recycling.

\section{Reuseable Components and Materials Feed Backwards}

Feeding materials backwards within the usage-maintenance-refurbishment process allows the maximum use to be gained from components, assemblies, and products and is an important part of the Embodied Energy reduction process, avoiding the need to procure new components and thus avoiding the expenditure of Energy of Primary Source (EPS). Many materials can be reused after being removed from the parent product during the maintenance or refurbishment process. These smaller elements may have some useful life remaining and can be fed backwards and reused within the Phase 2 Life Cycle. Products that have been maintained can be fed backwards to enter the usage cycle once again. Some products, such as vehicles can be maintained almost indefinitely and experience several life extensions, being fed back with full serviceability after each maintenance procedure.

Refurbishment is also a major feed backward element for products/materials since the whole product is renewed and re-presented as almost-new. As such, a refurbished product re-enters the usage/maintenance cycle once again.

Components and assemblies which are removed during the maintenance and refurbishment processes may still possess some useful life. These can also be fed backwards to an appropriate stage within Phase 2 Life Cycle. 
Feed backwards is used to great advantage within the vehicle industry. Many parts of used components are removed from end-of-life vehicles and resold to supplement damaged components on similar mark vehicles. These avoid the requirement for procuring new components thus saving the Energy of Primary Source (EPS).

\section{Data Feedback}

Perhaps one of the most difficult aspects to achieve is that of data feedback and yet it can be argued that it is one of the most important since it reflects real usage and possibly real difficulties in executing the Embodied Energy reduction plan. Data feedback informs the design team of usage trends, maintenance aspects, sacrificial component requirements, etc. Products may be distributed globally yet data need to be fed back to the design function residing in only a few places on the globe. Clearly a data highway is required.

Matsokis and Kiritsis (2010) suggested that this presents a new sustainable frontier and puts forward Kiritsis's data management process called Product Life-Cycle Management (PLM) which proposed that product information can be collected and disseminated throughout an organisation. The package encompassed the use of Product Life-cycle Management (PLM) of usage, refurbishing, and disposal so that closed-loop life cycle management (CL2M) could be achieved, the objective of which is to continually improve design, manufacturing, use, and end-of-life handling of products maintaining the most efficient energy resource level.

The PLM data acquisition and distribution structure are ideal to combine with the TDCMS, capturing the information gathered by the Sustainable Life Value (SLV) scheme and disseminating it to appropriate elements within the TDCMS structure. Kiritsis (2011) concedes that the technology is in its infancy, but with such a system in place, producers will be provided with complete data about modes of use, conditions of retirement, and disposal of their products.

Främling, Holmström, Loukkola, Nyman, and Kaustell (2013) extended the PLM methodology to include sharing information through smart products and networks and suggested that communication between devices and systems can improve energy efficiency by reducing energy consumption, extrapolating user behaviour, and integrating energy supply and demand. Armed with these data the design team can create new products with improved features. It should be emphasised that this process is successfully undertaken in several industries but is largely used to enhance the customer "experience". This could mean more engine power in vehicles, or perhaps adding a second handle to make the device more portable. The data are also useful from a sustainable point of view where modifications can be made to a product aimed at reducing Phase 2 Embodied Energy. For instance, lengthy maintenance periods may be the result of components that are difficult to access or that sacrificial components are difficult and time-consuming to remove. Changes in the product design can then be made to improve access and improve component removal rates.

Kerley, Wynn, Eckert, and Clarkson (2011), have recently changed their aircraft engine marketing strategy. Instead of selling the engines with the completed aircraft the engines are now leased which means that RR is responsible for maintenance and refurbishment. RR now controls materials input and outflow to and from the engine but more important information flows back to the management structure and into the design function. Though in its early stages, there have already been designed changes to inaugurate speedier, simpler engine maintenance. This is driven by safety and cost rather than any perceived Embodied Energy Reduction but it shows that such systems already exist and can be used to apply EER with a slight change in management approach. 
Data taken from, say refurbishment, later in the Phase 2 Life Cycle can be used to determine which components wear quickest and those components that are part worn and may be fed back to be reused. Recycling rates can also be assessed linking ease of recycling and the energy required for recycling and comparing that to the energy saved by avoidance of the primary sourcing of materials.

The fed-back data from all aspects of the Phase 2 Life Cycle can then be analysed and used on several levels:

- To compare the actual Embodied Energy to that originally predicted by the design function;

- To enhance the product through design iteration thereby using less Embodied Energy;

- To improve maintenance time and techniques through more sensitive design;

- To identify high wear components and improve their longevity by better design or by selecting more robust components.

\section{Predicted Phase 2 Life Cycle Embodied Energy}

During the creation process Phase 1 Embodied Energy can be measured up to the time when the product leaves the factory. When the product enters into the realm of the consumer, Embodied Energy needs to be predicted since this is in the future of the product and is largely out of the direct control of the creation team. Nevertheless it is important that the creation team predicts the Embodied Energy performance through each of the Phase 2 Life Cycle elements.

It is most likely that such an exercise will predict Embodied Energy usage and energy harvesting in the most idealistic situations. This is excusable when creating a new product because there are no data upon which to base realistic projections. It is a different situation with a product that has been already in the field. Maintenance, refurbishment, and replacement of parts are already underway and an efficient information feedback system can allow the creation team to compare realistic Embodied Energy data with their original predictions. Furthermore, original predictions relating to component wear and replacement may differ from the practical data returning from the field. With this information the design team can now implement design iterations and component changes to improve performance and reduce Embodied Energy for future products.

\section{Reliability Centred Maintenance Introduction}

It is clear that the logistics of implementing the Phase 2 Life Cycle element of the TDCMS is an enormous task, complicated by the global nature of products and their multiplicity of components. It makes sense therefore to embrace current maintenance and refurbishment best practice since these are the core elements within the Phase 2 Life Cycle.

Reliability Centred Maintenance (RCM) has been used and applied for several decades by such notables as the US Navy Submarine Service, Allen (2014), and the Royal Navy, Steven (2014), along with various aircraft manufacturers and operators. As the title suggests it is related to reliability through efficient maintenance techniques, providing a framework that defines a complete maintenance regime, explained by Sandham (2013).

The tools of the RCM maintenance regime are as follows:

- Planned Preventative Maintenance (PPM)

- Predictive Testing and Inspection (PTI)

- Reactive Maintenance (Repair when failed) (RA)

- Proactive Maintenance (PM) 
In practice these four features provide the mechanism for maintenance engineers to maintain the function of equipment, keep large systems operational, and ensure reliability. Some other key elements of this approach, according to Allen, are that:

- Acknowledges design limitations

- Driven by safety and economic concerns

- Treats a system as a "living system"

The system creates an efficient environment where possible failures are identified and dealt with in a planned manner. Furthermore information and in some cases, components are fed back to be reused.

The system, according to Sandham (2013), defines failure modes and defines failure risks as follows:

- High risk: life support systems and components that can cause significant disruption;

- Medium risk: diagnostic instruments and components that can fail with limited redundancy, e.g. a single headlight bulb failure in a vehicle;

- Low risk: components that make the overall system comfortable, e.g. interior vehicle lighting.

\section{RCM Incorporation Into Phase 2 Life Cycle}

The RCM system has been developed to ensure that maintenance is predictive, reactive, and efficient with the aim of sustaining systems long lived. The drivers for applying RCM are normally safety and cost reduction. Properly applying the system can be very efficient but information and material flow are usually confined to the closeted maintenance cocoon. It is interesting to note that the "design limitations" (Sandham, 2013) are acknowledged but there is often little feedback to the design function to enable design improvements. Furthermore within the RCM system there is little provision for end-of-life equipment disposal.

The advantage of using RCM within the Phase 2 Life Cycle is that the core component of maintenance is already defined and well-established in great detail in terms of operation and application. It is therefore proposed that the standard RCM process is modified to encompass sustainable techniques where the focus is broadened to include Embodied Energy Reduction through reuse and recycle, longevity of the system and components. The Total Design Control Management Process has also been modified so that RCM becomes a central component but now incorporates refurbishment. The new program integrates RCM with TDCMS across both Phase 1 Life Cycle and Phase 2 Life Cycle. The whole system can be seen in Figure 3, which is modified from Figure 2.

Within TDCMS there is more emphasis on feed forward of materials than the original RCM process. This encourages end-of-life disposal and feedback of materials to reuse and recycle. The original RCM tends to be a closed system where information does not leak out to management or design functions. A major improvement is that data can be fed back to the various elements of the TDCMS model. These data should include:

- Time required for maintenance (defining Embodied Energy usage can be defined)

- Time required for refurbishment (defining Embodied Energy usage can be defined)

- Quantity and a specification of replaced components

- Embodied energy value of replacement parts;

- Reason for replacement

- Parts that have been repaired (re-welded/re-machined)

- Destination of replaced components (recycle, reuse) 


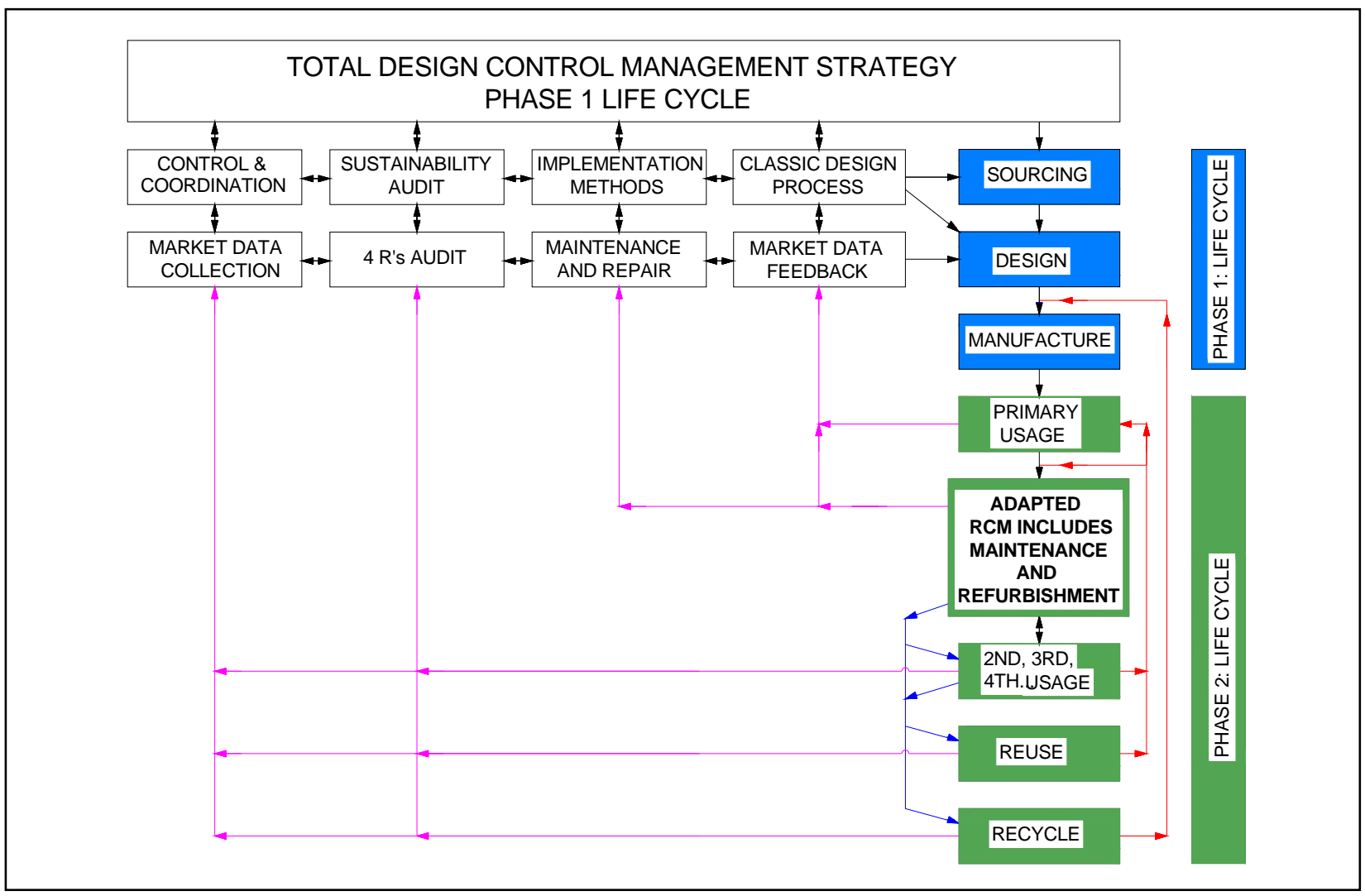

Figure 3. RCM/TDCM incorporation model.

The above general list is not exhaustive and could be improved when the detail is taken into consideration for the type of maintenance/refurbishment and also when the industry sector is considered.

The aim of this information feedback is to inform the design function so that product life cycle design improvements can be made through the design iteration process.

\section{The Benefits of Combining TDCMS and RCM Systems}

In general the aim of an RCM program is to reduce monetary expenditure but there are other elements which may be just as important such as safety and may take precedence over saving money. The introduction of Embodied Energy Reduction (EER) enhances and improves the RCM program by combining refurbishment and creates an information feedback route to the design team and the TDCMS management team. The normal attributes of RCM are listed as follows:

- reduce cost expenditure

- improve longevity

- improve reliability

- improve safety

The incorporation of a modified RCM strategy (maintenance and refurbishment) within the Phase 2 Life Cycle adapts the TDCMS model, so that Embodied Energy Reduction can be based on a current, well-tried RCM system. TDCMS can therefore be enhanced and made practicable by the qualities listed above plus the attributes brought to TDCMS by the focus in the reduction of Embodied Energy, the main points of which are listed below: 
Attributes of the Embodied Energy Reduction Programme

- reduce Embodied Energy usage.

(1) increase in the life of a product;

(2) reusing or recycling components;

(3) reducing the time to apply maintenance or refurbishment;

(4) reducing the need to purchase new products (thus reducing EPS).

- information feedback (to the design function and the TDCMS management team).

- create an information absorptive environment to encourage regeneration and iteration of products leading to their EE improvement.

- reduce the Embodied Energy applied to new products.

\section{Sustainability Centred Maintenance (SCM)}

Amalgamation of the TDCMS information feedback with the RCM system refocuses on the maintenance function from reliability to sustainability and can thus be renamed Sustainability Centred Maintenance (SCM). An efficient RCM program will have previously reduced Embodied Energy, except that such energy reduction is usually considered a minor facet of the program and is aimed at reducing direct energy application such as transport energy or powering machine tools. Energy reduction here is directly linked to its cost. The application of SCM feedback information now empowers the TDCMS/Design Team to ensure that ALL energy use is included in achieving the goal of improving the energy input efficiency and longevity of the product. This has far reached effects such as implementing smart factories, sustainable transport, localised sourcing, and long life component selection, etc.

The reduction of input energy is synonymous with reducing cash expenditure. It is also true that the implementation of an EER strategy and the incumbent systems can be quite costly to install. It was noted by Allen, however, that the Initial cost of RCM systems was regained over time and eventually provided significant savings.

\section{Evolution of a Sustainability Enhancement Program (SEP)}

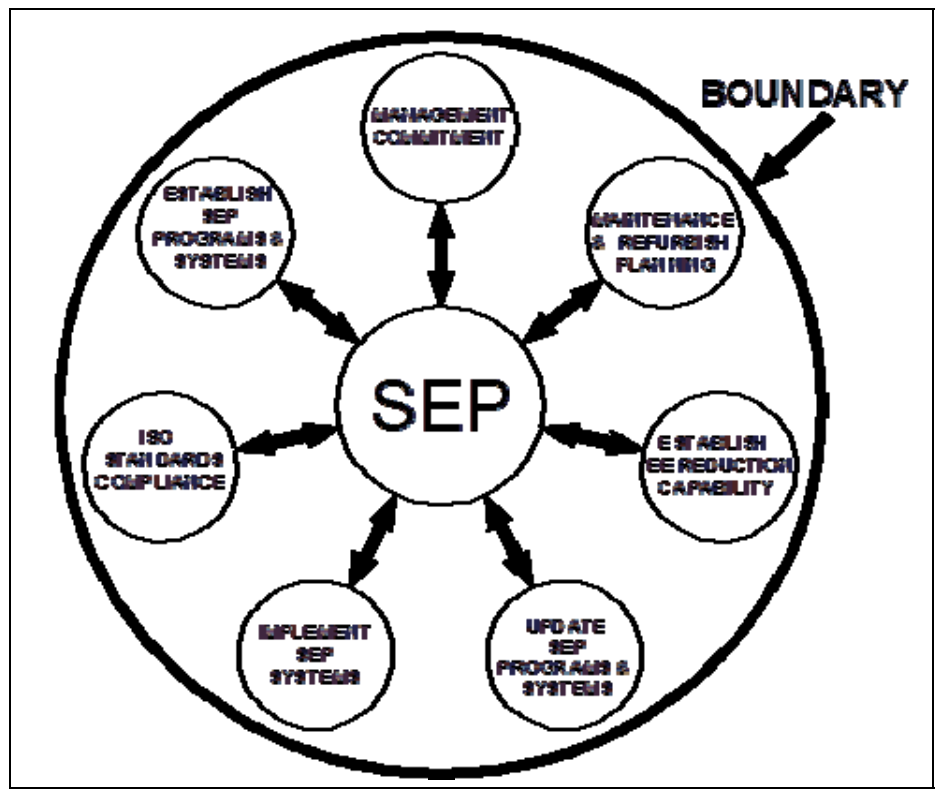

Figure 4. Characteristics of sustainability enhancement programme. 
A program such as the integration of RCM within the TDCMS cannot be efficiently applied in a piecemeal fashion. Corporate commitment is necessary at all levels with appropriate planning methodology, implementation techniques, personnel training, and programme updating. Any large and complex program such as SEP requires a plan of implementation and running procedure. The characteristics of such a system can be seen in Figure 4 and include:

- management commitment

- SEP implementation strategy

- establishment of SEP program systems

- establishment of an SEP system boundary

- compliance with ISO standards and regulations

- Embodied Energy Reduction capability

- planning of maintenance and refurbishment procedures

- updating of SEP procedures

\section{Benefits of SEP Implementation}

The benefits from implementing such a system include:

- The design function and the management team have full knowledge of the product in service.

- Implementation of a life cycle overviews interpretation pertaining to new products.

- Products are no longer isolated in the usage environment since information feedback from SCM informs the TDCMS team of impending problems.

The following example outlines a case where feedback from the maintenance function alerts the management/design team to a product fault.

The vehicle industry has occasionally recalled many millions of vehicles because a fault has been discovered whilst the vehicle is in use or being maintained. Toyota has recently recalled 6.4 million vehicles worldwide due to an airbag fault $B B C$ News, and would only have implemented the recall with a design solution ready to be applied. Continuous monitoring of a product, as that applied by Toyota, within the Phase 2 Life Cycle creates an environment of continuous process improvement.

Toyota, as with many other similar companies appears to apply an SCM/TDCMS/SEP strategy but the motivation is reducing costs, reducing complaints, and safety and perhaps improvement of reputation. EER is not usually considered a priority.

The introduction of an SEP strategy would cover all the motivational elements listed above and reduce Embodied Energy within the Phase 2 Life Cycle. SEP techniques can then be tailored to a particular product set integrating elements such as maintenance, refurbishment, recycling, and re-use into a cohesive combined strategy.

\section{ISO European Standards}

Any new environmental management system requires adherence to legislation and the most appropriate standards. The ISO standards 14001 and 14040 [12, 13] represent some of the most modern thinking and it is proposed that these guidelines are applied to an overall management control system dedicated to reducing EER in components, products, and systems. SEP provides an umbrella management system that controls and operates practical as well as systemic elements. The incorporation of the ISO 14040 Standard can be directly 
applied to SEP methodology shown in the diagram in Figure 5. ISO 14040 relates to SEP systemic control and forms a framework of background policies, aims, data processing, quality, and relevance through impact assessment.

There are overlaps between the ISO Standards but it is clear that ISO 14001 relates to practical terms in the TDCMS planning, operation, implementation, and monitoring, etc. And the two standards create a resilient framework for implementing, applying, reporting, and managing both TDCMS and SEP management strategies.

\section{ISO Standards Overview}

ISO 14001-2004 Environmental management systems: sets out requirements for managing environmental systems. In particular when implementing TDCMS many of the requirements for such a system are proposed in the "requirements" of the standard. Much of the responsibility for implementing an environmental management policy such as TDCMS is placed on the management team of the organisation and refers to the "organisation" as applying, maintaining, and auditing such a policy. The Standard outlines elements which must be installed in such an environmental management policy. Some of the major items are listed as follows:

- planning

- implementation and operation

- communication

- documentation

- operational control

- monitoring and measurement

- internal audit

These are some of the requirements of the standard, but they match the objectives of the TDCMS management system.

ISO 14040-2006 Environmental management-Life cycle assessment-Principles and framework: provides more of an overview of the aims and scope of an environmental management policy accommodating the SEP scope and aims. Within such an environmental management policy the Standard projects the use of a Life Cycle Assessment (LCA) comprising the following main elements:

- the goal and scope definition

- inventory analysis

- impact assessment

- interpretation of results

When incorporated into SEP these four basic management overview tools ensure that the environmental enhancement is properly targeted. Interestingly there are no cost implications mentioned but more importantly the ISO Standard uses the metric of energy in order to quantify the various processes. The ISO Standards correctly applied complies completely with the approach taken by the SEP \& TDCMS management models. The use of Embodied Energy as a metric ensures that there is a quantitative value that can be used throughout the system as currency in Embodied Energy Reduction (EER). The diagram in Figure 5 shows how the SEP and TDCMS management systems are applied within the envelope of both ISO's. The Standards also require a control boundary ensuring that spurious inputs are eradicated and the Embodied Energy relating to a particular product or system is not contaminated. 


\section{Conclusion to Phase 2 Life Cycle SEP Implementation}

The Phase 2 Life-Cycle Model is used in part in several industries though only a few industries, e.g. vehicles, aircraft, and military which developed cohesive overview systems. When these systems are applied as suggested in the Phase 2 Life-Cycle model the drive is to improve the longevity of the system which improves reliability, safety, and cost. There may be attempts to reduce directly applied energy such as in diesel fuel or perhaps electricity for machine tools. There may be some exceptions but generally Embodied Energy reduction is rarely considered. The passenger vehicle industry comes close to applying the whole system but reliability and cost reduction are the main priorities. Few industries, if any, apply Phase 2 Life-Cycle systems in order to reduce Embodied Energy. Commercially, cost is a major driver and even though there may be the best sustainable solutions available, they will not be implemented if they are not cost-effective.

As with the RCM system there are high risk, medium risk, and low risk elements relating to the EER program. It may be necessary to avoid maintaining low EE items such as interior lighting, simply because it will be too costly in monetary terms. It is within the designer's influence to overview the entire life cycle of a product from sourcing materials through to end-of-life disposal. In order to perform this task properly it needs to be a management process in place which has become known as the Total Design Control Management System (TDCMS). As to function properly TDCMS requires feedback of information from the product during its life.

Phase 1 Embodied Energy totals the energy applied to the product until it leaves the factory. Phase 2 Life-Cycle Embodied Energy is much more difficult to predict however with a strategic management system such as SEP and TDCMS, plus SCM, there can be materials feed-forward, feed-backwards, and more importantly dataflow from the field into the TDCMS. This then allows the design team to make changes and iterate the design to become more Embodied Energy efficient with each modification.

The overview management strategy, TDCMS combines Phase 1 Life Cycle and Phase 2 Life Cycle in an overall Embodied Energy Reduction program known as SEP. This combines Phase 1 Embodied Energy measurement and Phase 2 Embodied Energy prediction/measurement to create information of feedback through the Sustainability Centred Maintenance Programme. The incorporation of the ISO Standards 14001 and 14040 has been used as a base framework and has guided the evolution of the whole umbrella management system that evolved into SEP. The ISO Standards have defined management processes, goals, boundaries, and procedures.

The management of sustainability in new products is proposed by the implementation of a system wide management strategy as follows:

SEP-Sustainability Enhancement Programme operates at executive level providing overview management, implementation authority, and funding.

TDCMS-Total Design Control Management Strategy is the middle level management system which controls, measures, and coordinates the day to day operation using the basic design process as the key guide.

SCM-Sustainability Centred Maintenance is the hands-on management system based at product level. It operates along-side standard maintenance processes providing a decision making framework, data monitoring, and feedback with data dissemination.

ISO 14000 Series Environmental Standards-provide a cohesive framework for each management level and incorporates strategies of control, feedback, data recording, and scope, etc. These standards also blend seamlessly with other management standards such as ISO 9001. 
The data produced by SCM need to be fed back to appropriate TDCMS. This could be achieved using adaptive information feedback introduced by Kiritsis (2011) and Främling et al. (2013) who have developed a system of "Closed Loop Product Life Cycle Management” (PLM). This system involves automatic reading of information from the product, often imbued with "smart" properties so that data can be directly fed through a “Big Data”system to various life cycle functionary's databases which are automatically updated. Further work would involve with exploring the system and linking it to particular elements of the TDCMS.

SYSTEM BOUNDARY

SUSTAINABILITY ENHANCEMENT PROGRAMME IN ASSOCIATION WITH

ISO 14040

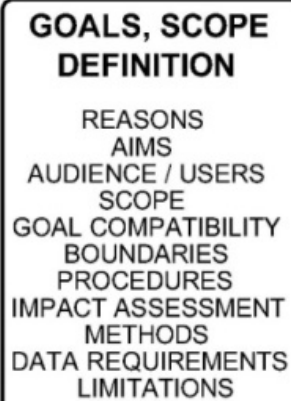

\section{INVENTORY ANALYSIS}

DATA COLLECTION INFORMATION ANALYSIS DATA QUALITY DATA VALIDITY DATA FLOW FUNCTIONAL RELEVANCE

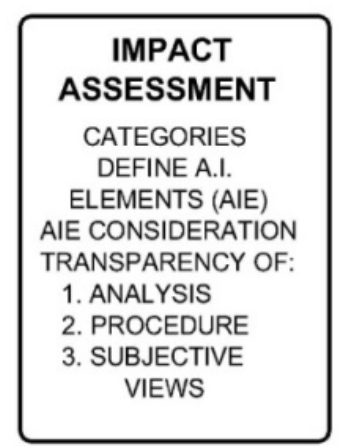

\section{1

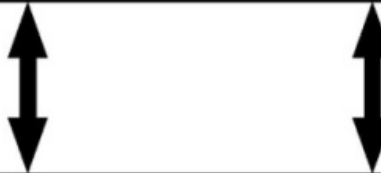 \\ TOTAL DESIGN CONTROL MANAGEMENT STRATEGY IN ASSOCIATION WITH \\ ISO 14001}

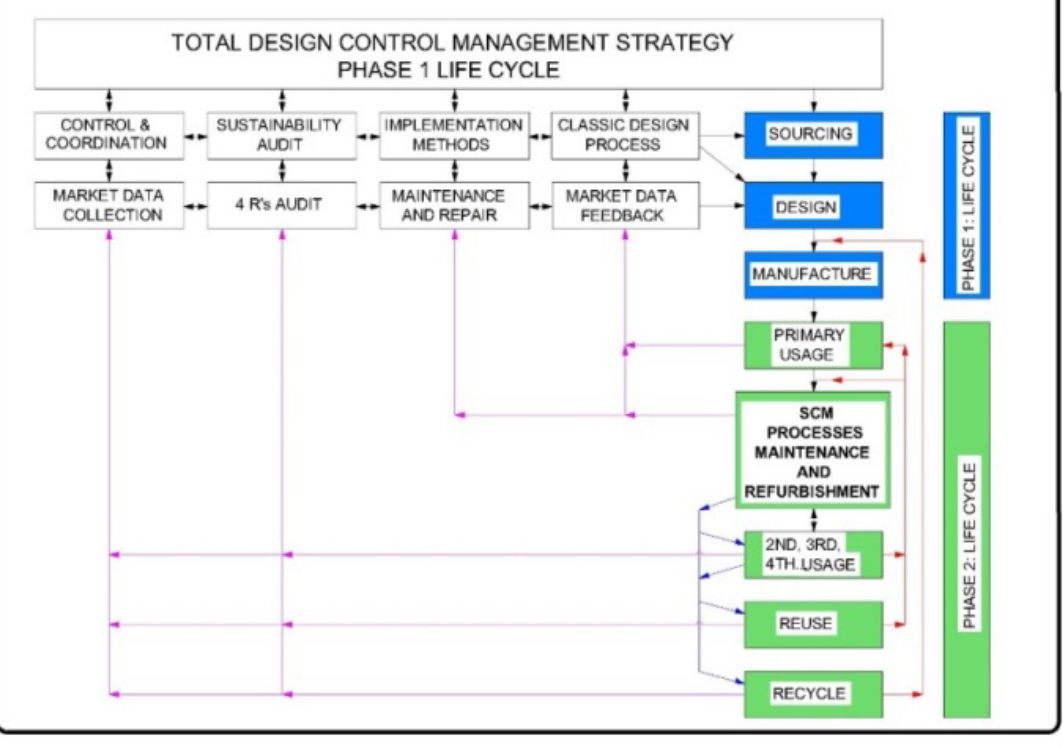

SYSTEM BOUNDARY

Figure 5. Sustainability Enhancement Program incorporating ISO standards. 


\title{
Literature Review
}

The review considers diverse publications which show how the normally used life cycle can be enhanced, principally by applying maintenance procedures (Kerley et al., 2011; Sandham, 2013) and a measurement system that uses Embodied Energy Ashby (2012) as a measurement parameter. The introduction of maintenance increases the longevity of the product thus avoiding the extraction of new resources. Energy is applied in every life cycle stage and is independent from product type or service, thus being an ideal metric. Using Life Cycle Analysis and contributions from several publications, a general management strategy was formulated which included feedback of information and materials (Takata, 2013). Information feedback theories were applied from the works of Främling et al. (2013) and Kiritsis (2011), thus creating a complete executive base management system which included SEP, TDCMS, and SCM.

\section{Glossary}

\author{
EE: Embodied Energy \\ EER: Embodied Energy Reduction \\ EPS: Energy of Primary Source \\ LC: Life Cycle \\ PV: Photo-voltaic
}

RCM: Reliability Centred Maintenance

SCM: Sustainability Centred Maintenance

SEP: Sustainability Enhancement Program

TDCMS: Total Design Control Management Strategy

\section{References}

Ashby, M. F. (2012). Materials and the environment. Elsevier. ISBN: 978-0-12-385971-6.

Allen, T. M. (2014). U.S. navy analysis of submarine maintenance data (RCM). Retrieved from http://www.plant-maintenance.com/articles/SubmarineMaintenanceDataRCM.pdf

BBC News: 2014: http://www.bbc.com/news/business-26950970 09/04/2014: Accessed 2014

Främling, K., Holmström, J., Loukkola, J., Nyman, J., \& Kaustell, A. (2013). Sustainable PLM through intelligent products. Engineering Applications of Artificial Intelligence, 26(2), 789-799.

ISO 14001. (2014). Environmental management systems-Requirements ISO Store: http://www.iso.org/iso/home/standards/management-standards/iso14000.htm: accessed 2015

ISO 14040. (2006). Environmental management-Life cycle assessment—Principles and framework: ISO Store: http://www.iso.org/iso/home/standards/management-standards/iso14000.htm accessed 2015

Johnson, A. D., Gibson, A. G., \& Barrans, S. M. (2011). The sustainable engineering design model: Necessity or luxury. International Institute for Informatics and Systemics (symposium). Florida.

Johnson, A. D., \& Mishra, R. (2013). Sustainability in engineering design (reported on Total Design Control Management Strategy (TDCMS)). International Conference on Sustainability, Technology and Education. Kuala Lumpur, ISBN (Book): 978-989-8704-00-9.

Kerley, W., Wynn, D. C., Eckert, C., \& Clarkson, P. J. (2011). Redesigning the design process through interactive simulation: A case study of life-cycle engineering in jet engine conceptual design. International Journal of Services \& Operations Management, 10(1), 30-51.

Kiritsis, D. (2011). Closed-loop PLM for intelligent products in the era of the Internet of things. Computer Aided Design, 43(5), 479-501.

Matsokis, A., \& Kiritsis, D. (2010). An ontology-based approach for Product Lifecycle Management. Computers in Industry, 61(8), 787-797. 
Sandham, J. (2013). Reliability centered maintenance (RCM). EBME. Retrieved from http://www.ebme.co.uk/articles/management/327-reliability-centred-maintenance-rcm: accessed 2016

Steven, G. (2014). Reliability-centred maintenance applied to military structures. Maintenance \& Asset Management, 25(4). Retrieved from http://www.stevenconsultants.co.uk: accessed 2015

Takata, S. (2013). Maintenance-centred circular manufacturing. 2nd International Through Life Engineering Services Conference, 11, 23-31. Retrieved from http://www.sciencedirect.com/science/journal/22128271/11 